\title{
Erratum to: Neuroprotective Effect of Natural Products Against Alzheimer's Disease
}

\author{
Musthafa M. Essa • Reshmi K. Vijayan • \\ Gloria Castellano-Gonzalez • Mustaq A. Memon • \\ Nady Braidy • Gilles J. Guillemin
}

Published online: 31 August 2012

(C) Springer Science+Business Media, LLC 2012

\section{Erratum to: Neurochem Res (2012) 37:1829-1842 DOI 10.1007/s11064-012-0799-9}

Several misspellings have been identified in our manuscript by Essa et al. 2012 (Neurochem Res DOI 10.1007/s11064012-0799-9) entitled "Neuroprotective Effect of Natural Products Against Alzheimer's Disease".

The corrections noted are:

Under the heading of Edible brain food and Blue berry, the botanical name should be Vaccinium myrtillus $L$ not Vaccinum angustifolium

Under the heading of Strawberry, please read Ericaceae instead of Ericeae

Please read the heading Papaya instead of Pappaya

The online version of the original article can be found under doi: 10.1007/s11064-012-0799-9.

M. M. Essa · R. K. Vijayan

Department of Food Science and Nutrition, College of Agriculture and Marine Sciences,

Sultan Qaboos University, Muscat, Oman

M. M. Essa - G. Castellano-Gonzalez - N. Braidy ·

G. J. Guillemin $(\bowtie)$

Neuroinflammation Group, Department of Pharmacology,

School of Medical Sciences, University of New South Wales,

Sydney, NSW 2052, Australia

e-mail: g.guillemin@unsw.edu.au

M. M. Essa

Developmental Neuroscience Lab, NYSIBR, 1050 Forest Hill

Road, Staten Island, NY 10314, USA
Under the heading of Green tea, Camellia sinesis should be replaced by Camellia sinensis

Under the heading of Saffron, please read Iridaceae instead of Iridacea

Under the heading of Pepper, please read Piper nigrum instead of Piper nigram and Piperaceae instead of Piperacea.

Under the heading of Herbs and Alzheimer's disease, please read Ginkgo biloba instead of Ginko biloba.

Under the heading of Poncirus trifoliate, the heading and the corresponding text should read as Poncirus trifoliata instead of Poncirus trifoliate

Under the heading of Paeonia suffruticosa, please read Paeonia suffruticosa instead of Paenoia suffruticosa

G. Castellano-Gonzalez

Neuroinflammation Group, St Vincent's Centre for Applied

Medical Research, Sydney, NSW, Australia

M. A. Memon

Washington State University, Pullman, WA, USA

N. Braidy

Faculty of Medicine, School of Psychiatry, University of New

South Wales, Sydney, NSW, Australia

G. J. Guillemin

Department of Behavioural Medicine, College of Medicine and Health Sciences, Sultan Qaboos University, Muscat, Oman 